\title{
Representação social de crianças acerca do velho e do envelhecimento ${ }^{1}$
}

\author{
Ewellyne Suely de Lima Lopes \\ Margareth Brandini Park \\ Universidade Estadual de Campinas
}

\begin{abstract}
Resumo
O objetivo do presente estudo constituiu-se em investigar a representação social de um grupo de crianças acerca do velho e do envelhecimento, tendo como base a teoria das representações sociais proposta por Serge Moscovici. Utilizando como metodologia desenho, entrevista semi-estruturada e brincadeira tematizada, 31 crianças, que haviam vivenciado encontros com velhos no contexto escolar, participaram do estudo, sendo 11 com idades entre oito e dez anos e 20 com idades entre cinco e seis anos. Os resultados indicaram uma representação social diversificada acerca do velho, englobando temas como características físicas, avós, doença, morte, limitações físicas, trabalho, atividades e heterogeneidade. Em relação ao envelhecimento, este é representado pelas crianças relacionado à passagem do tempo, à qual todos os indivíduos estão sujeitos.
\end{abstract}

Palavras-chave: representação social; crianças; velho; envelhecimento

\begin{abstract}
Children's social representation about old people and aging. The goal of the present study was to investigate the children's social representation about old people and aging. The social representation theory by Serge Moscovici was used as theoretical support. Drawing, semi-structured interviews and oriented children play were employed to investigate 31 children, 11 aged between eight and ten years old and 20 between five and six years old. The results indicated a diversified social representation about old people, in which themes like physical characteristics, grandparents, illness, death, physical disabilities, employment, activities and heterogeneity are present. The children regarded aging as the passage of time, a process to which everyone is subjected.
\end{abstract}

Keywords: social representation; children; old people; aging

$\mathrm{S}$ egundo Beauvoir (1990), as representações do velho e da velhice, que se refletem no modo como são tratados, resultam tanto das circunstâncias materiais de cada sociedade quanto de seu sistema de valores e crenças, sofrendo mudanças em sociedades diferentes e ao longo do tempo dentro de uma mesma sociedade.

Áries (1986), por sua vez, afirma que o conceito de velhice a partir da Idade Moderna passa por três momentos distintos. Nos séculos XVI e XVII, a velhice era o tempo dos anciões decrépitos, assumindo um caráter pejorativo, pois em decorrência do alto índice de mortalidade na época, não era comum aos indivíduos alcançar essa etapa da vida. Posteriormente, ocorreram duas etapas no processo de mudança das imagens de velhice. A primeira, que durou até o século XIX, tinha o conceito de velho relacionado à idéia de ancião respeitável. Na segunda, o ancião desaparece para dar lugar ao "homem de certa idade" e aos "senhores e senhoras muito bem conservados", sendo as idéias biológica e moral da velhice substituídas pela idéia tecnológica da conservação.
Barreto (1992), referindo-se à realidade brasileira, afirma que no século XIX o velho era considerado sábio. No século $\mathrm{XX}$, entretanto, percebe-se uma pressão para que a velhice seja negada, valorizando aqueles que conseguem "disfarçá-la de jovem", tanto física quanto psicologicamente.

Para Debert (1999), há uma tendência contemporânea à revisão dos estereótipos associados à velhice. A idéia de perdas e degenerescência dá lugar à idéia de que a velhice pode ser uma etapa de prazer, conquistas e realizações de sonhos que haviam sido postos de lado em outros momentos da vida. Featherstone (1998), a seu turno, aponta para uma "desconstrução" da categoria velhice, igualando-se velhos e adultos jovens, seja no sentido de que estes podem também ser alvos de doenças, seja no sentido de que aos velhos é associada uma imagem mais positiva no Ocidente.

Atualmente percebe-se, por um lado, imagens de velhos que procuram manter o controle sobre seus corpos e relativa juventude, ativos e dispostos a realizar sonhos e satisfazer seus desejos; e, por outro, imagens de velhos pobres, doentes, 
solitários, assexuados e abandonados à sua sorte. Desse modo, coexistem diferentes imagens de velhos na sociedade contemporânea.

Essa coexistência de imagens pode ser atribuída ao que Debert (1999) chamou de duplo movimento de transformação da velhice em preocupação social. Numa primeira perspectiva, essa fase da vida é socializada e torna-se objeto de preocupação e intervenção por parte do Estado e de instituições privadas, sendo relacionada à decadência física e à perda de papéis sociais. Concomitantemente, ocorre o processo de reprivatização da velhice, no qual a responsabilidade sobre o velho que se é ou será é totalmente atribuída ao indivíduo, podendo a velhice ser gratificante, sob esta perspectiva.

Essa variedade de imagens e, conseqüentemente, de representações, relaciona-se também à criação de etapas intermediárias do envelhecimento que, conforme Debert (1999), têm se proliferado atualmente. Surgem, por exemplo, a meiaidade, a aposentadoria ativa e a terceira idade. Utilizados para designar a velhice de modo menos depreciativo, tais termos são incorporados ao vocabulário dos grupos sociais e carregam uma gama de significados que influenciam a (re) construção das representações sociais acerca do velho e da velhice. Nesse sentido, vêem-se velhos se reconhecendo como idosos e participantes da terceira idade, ao mesmo tempo em que denominam velhos, aqueles que foram acometidos pelos sinais indesejáveis do envelhecimento. Esse movimento revela a intenção de posicionarem-se como indivíduos ainda ativos e capazes de viver a vida plenamente, seguidores das recomendações para um envelhecimento bem-sucedido.

Park (2000, 2004) pontua que a substituição do termo velho por idoso leva a um deslocamento da discussão sobre a velhice, colocando a longevidade em foco e deixando de discutir a questão da função social do velho. Tal deslocamento é favorável à manutenção dessa classe etária como mercado consumidor potencial e de sua imagem como improdutiva. E, é por esse motivo que neste trabalho opta-se pela utilização do termo velho.

No que se refere a estudos que investigam crenças, atitudes, percepções e representações sociais do velho, da velhice e do envelhecimento no cenário brasileiro, podem ser destacados os trabalhos de Veloz, Nascimento-Schulze e Camargo (1999), Novaes e Derntl (2002), Almeida e Cunha (2003) e, Araújo e Carvalho (2004). Na literatura gerontológica internacional distinguem-se trabalhos que investigam crenças e atitudes de crianças em relação ao velho e à velhice, como os de Lichtenstein et al. (2003), Pinquart, Wenzel e Sörensen (2000) e Newman, Faux e Laurimer, (1997). Nos resultados dos estudos mencionados predominam relações entre os objetos estudados e aspectos negativos, estando os conteúdos encontrados freqüentemente relacionados a perdas biológicas, de laços familiares e do ritmo de trabalho. Surge também, a idéia do velho como portador de experiência e sabedoria, o que parece servir como compensação pelas perdas referidas. De modo geral, tais conteúdos parecem impregnados de preconceitos que apontam o velho como improdutivo para o trabalho, dependente dos que o cercam, doente e solitário.

Entender como a velhice, o velho e o envelhecimento são percebidos e representados oportuniza a compreensão de comportamentos e sentimentos para com estes, seja por parte da sociedade ou dos próprios velhos. Assim, estão em pauta crenças, explicações e definições a respeito de tais objetos sociais, isto é, o conhecimento que os grupos sociais elaboram e utilizam para compreender e lidar com estes, portanto, suas representações sociais.

Por representação social, Moscovici (1978) entende "um corpus organizado de conhecimentos e uma das atividades psíquicas graças às quais os homens tornam inteligível a realidade física e social, inserem-se num grupo ou numa ligação cotidiana de trocas, e liberam os poderes de sua imaginação" (p. 28). Desse modo, as representações sociais são uma forma de conhecimento elaborada por determinado grupo sobre um objeto social relevante, assumindo importância ao exercer as funções de direcionar comportamentos e facilitar a comunicação entre os membros do grupo que as compartilha.

As representações sociais podem ser consideradas uma versão contemporânea do senso comum, tendo Serge Moscovici, idealizador da teoria das representações sociais, realizado um trabalho de reabilitação do mesmo, segundo Arruda (2002). O próprio Moscovici (2005) relata que, ao iniciar seus estudos, procura compreender e reabilitar o conhecimento comum, considerando-o como algo moderno e não-primitivo, que se origina parcialmente da ciência ou universo reificado e ganha lugar no universo consensual.

Conforme Sá (1993), ao universo reificado cabe a função de apresentar a novidade, a qual gera certo desconforto quando passa a circular no universo consensual, por ainda não estarem estabelecidos os códigos sociais para lidar com esta. Diante de tal desconforto, os indivíduos mobilizam-se, por meio das atividades intelectuais em suas interações cotidianas, a fim de restabelecer a ordem perdida. Assim, tem-se que a criação de uma representação social dá-se no momento em que o novo, usualmente trazido por divulgadores científicos, é incorporado ao conhecimento que já é de posse dos indivíduos e do grupo quando, por meio da arte de conversação, pensam juntos sobre os mesmos assuntos.

A elaboração das representações sociais compreende dois processos: a objetivação e a ancoragem. Moscovici (2005) afirma que objetivar significa transformar uma noção abstrata em algo concreto, tornando-a palpável e objetiva, dando uma forma específica ao conhecimento que se tem a seu respeito com a finalidade de reproduzir algo não-familiar entre o que pode ser visto, tocado e controlado. É um processo que permite aos indivíduos, materializar um conceito, comparando-o a algo que lhes seja visível e concreto, tal como quando relacionam Deus à idéia de pai ou o inconsciente a um órgão do corpo humano.

Sobre a ancoragem, Sá (1993) dispõe que esta visa à integração do novo objeto a um sistema de pensamento social preexistente, por meio de classificação e nomeação. Para classificar, os indivíduos escolhem um dos paradigmas ou protótipos existentes em sua memória, com o qual o objeto será comparado, e decidem se este pode ou não ser incluído na classe em questão. No processo de nomeação, inclui-se o objeto num complexo de palavras específicas, localizando-o na matriz de identidade da cultura. Assim, o objeto deixa de ser estranho 
e pode ser descrito, distinguindo-se dos demais objetos por características e tendências que lhe são atribuídas.

Duveen (2005) ressalta o caráter dinâmico das representações sociais, argumentando que elas estão sujeitas a mudanças, seja pela emersão de novas representações ou pela re-elaboração de representações já existentes. Pontos de conflito, falta de sentido ou algo não-familiar dentro das estruturas representacionais de cada cultura servem de estímulos para tais alterações. Moscovici (2005) salienta que as representações estão sujeitas a mudanças vertiginosas em consonância com a velocidade da sociedade, na qual surgem, se adaptam e desaparecem.

As representações sociais estão presentes na vida dos indivíduos desde a primeira infância, sendo a criança inserida em um mundo estruturado por elas. Conforme Moscovici (2005), a influência destas no desenvolvimento do indivíduo se dá desde muito cedo, estando estampada no modo como este percebe o mundo e se posiciona nele. Duveen e Lloyd (2005) destacam que desenvolver a competência adequada para participar como ator na sociedade implica compartilhar as representações sociais desta. Desse modo, a criança trabalha para estabelecer contato com as representações que lhe são apresentadas, a fim de fazer parte do grupo social. Como ator social em interação com indivíduos e instituições circundantes, a criança apreende as informações e as elabora, contribuindo para a construção da sociedade com suas representações sociais.

Os objetivos da dissertação que deu origem a este relato eram investigar a representação social de dois grupos de crianças sobre a velhice e os velhos e a possível influência do encontro intergeracional no processo de formação dessa representação (Lopes, 2006). No presente artigo, entretanto, serão apresentados apenas os resultados relacionados ao primeiro objetivo.

\section{Método}

O primeiro grupo foi composto por 11 crianças com idades entre oito e dez anos (quatro meninas e sete meninos), tendo os referidos contatos com velhos ocorrido dois ou três anos antes da coleta de dados. O segundo grupo foi formado por 20 crianças, com idades entre cinco e seis anos (sete meninas e 13 meninos) que realizaram atividades envolvendo velhos no ano em que se deu a coleta de dados. Todas as crianças residiam em um dos bairros afastados do centro comercial de Jarinu (SP) - cidade com cerca de 21 mil habitantes e economia baseada na produção agrícola. Pertencentes a famílias de classe econômica de baixa renda, as crianças eram filhas de pessoas que trabalhavam em atividades ligadas à zona rural.

Segundo Arruda (2002), Moscovici propõe certa liberdade aos pesquisadores quanto à estratégia metodológica a ser utilizada, objetivando permitir-lhes desenvolver a teoria e a criatividade, pois o interesse maior está em descobrir, e não em comprovar. Desse modo, e tendo como referência pesquisas realizadas com crianças, optou-se pela utilização do desenho aliado à entrevista semi-estruturada e da brincadeira tematizada como instrumentos de investigação.

O desenho é considerado um modo singular de expressão de conteúdos pessoais e sociais. Demonstra-se útil para a coleta de dados sobre a representação social da criança devido a seu potencial de revelar indícios tanto das informações de que esta dispõe acerca do objeto social que representa, quanto de seu posicionamento diante do mesmo. Assim, solicitou-se às crianças a confecção de um desenho que representasse um ou mais velhos, conforme aquilo que pensassem sobre estes quanto aos seguintes temas: moradia, atividades desenvolvidas, características físicas, condições de saúde e locais onde usualmente são encontrados.

Souza Filho (1993) ressalta que o desenho como instrumental para investigar representações sociais precisa ser acompanhado por verbalizações, a fim de apreenderem-se as intenções e os significados associados pelos sujeitos. Baseando-se nessa linha de pensamento, foram realizadas entrevistas semi-estruturadas, utilizando o desenho da criança como estímulo inicial e perguntas norteadoras relacionadas aos temas propostos para a confecção deste. Todavia, durante as entrevistas surgiram oportunidades para a exploração de outros temas, estes pontuados pelas próprias crianças.

A utilização da brincadeira como forma de conhecer e compreender o pensamento infantil é corroborada por Silveira (2005), que a considera uma forma de expressão da criança. Além disso, o brincar está relacionado com a realidade social e cultural à que a criança está vinculada. Partindo desses pressupostos, utilizou-se a brincadeira tematizada ("faz-deconta") como um terceiro instrumento metodológico, pois ao solicitar às crianças que "fizessem de conta" que eram velhos, as mesmas utilizariam seus conhecimentos e percepções sobre o que é ser velho para brincar. Antes de iniciar a brincadeira em si e em parceria com a professora, houve um momento de diálogo com as crianças, durante o qual se falou sobre velhos e foram retomadas as atividades de desenho e entrevista. Posteriormente, as crianças foram convidadas a brincar, considerando os temas já tratados durante a confecção do desenho e a entrevista. Todos os procedimentos foram registrados, conforme anuência das crianças e dos responsáveis pelas mesmas.

Entrevistas e brincadeiras foram transcritas, atentando-se nas últimas não somente para seu desenrolar, mas também para gestos, posturas corporais, falas, instruções e comentários feitos pelas crianças durante o brincar. Procedeu-se à análise de dados aliando transcrições e desenhos num único corpo de dados, do qual emergiram as categorias temáticas estruturadoras da representação social das crianças.

Vale ressaltar que, mesmo tendo sido utilizados tópicos norteadores para coleta e análise de dados, foram as falas das crianças que, primordialmente, delinearam as categorias temáticas, levando até mesmo ao estabelecimento de categorias não definidas inicialmente pela pesquisadora. Assim sendo, à medida que determinado tema mostrava-se relevante e freqüente no corpo de dados, estabelecia-se uma categoria temática.

\section{Resultados e discussão}

A apresentação dos resultados será estruturada em dois tópicos: O envelhecer: porque uma pessoa é velha e Como é uma pessoa velha, sendo este dimensionado em seis categorias temáticas. 


\section{Como é uma pessoa velha}

$\mathrm{Na}$ categoria Rugas e cabelos brancos destaca-se a importância que as crianças conferiram às características físicas como forma de reconhecer os velhos. Rugas, pele seca, cabelos, sobrancelha e barba brancos, ausência de dentes, voz enfraquecida e corpo encarquilhado são os sinais físicos freqüentemente apresentados.

Entrevistadora (Ent) - ... O que que ela tem, que faz você falar que ela é velha?

$\mathrm{AnC}-\mathrm{Ah}$, a aparência, né?

Ent - Aparência? Como é que é essa aparência?

AnC - É... o rosto é enrugado. (Menina, 10 anos)

Bar-Elas têm cabelo branco, tem barba e sobrancelha branca.

(Menina, 6 anos)

O corpo e a aparência física são meios que os seres humanos utilizam para se reconhecerem, estabelecer relações e comportamentos uns para com os outros. Featherstone (1998) chama a atenção para o fato de que a observação dos corpos é a base para julgamentos sobre o status e o valor dos outros, sendo o corpo humano uma entidade visível que desempenha um papel relevante na comunicação entre as pessoas. Conforme ressalta Magro (2003), as identidades etárias são construídas nas relações entre os grupos de idade, em que os diferentes corpos se encontram e dialogam entre si pelas percepções de diferenças físicas e comportamentais. No encontro entre uma criança e um velho, as diferenças entre as imagens corpóreas e existenciais delimitam o grupo de idade a que um e outro pertencem, permitindo que cada um reconheça o outro como membro de dada classe etária. Atribuir rugas e cabelos brancos aos velhos, ao lado de outros aspectos físicos, identificando-os a partir desses caracteres visíveis e palpáveis, é uma forma dessas crianças materializarem o conceito de pessoa velha, objetivando-o no processo de construção da representação social.

Entretanto, ainda que os cabelos brancos tenham sido citados como característica marcante dos velhos, algumas crianças apontam a existência de outras possibilidades para a cor dos cabelos destes, indicando um movimento de relativização dentro de sua representação de velho. Ou seja, uma pessoa que tem cabelos brancos é velha, mas uma pessoa velha pode ter cabelo de outra cor, porque atualmente essa é uma possibilidade apresentada pela mídia e pela própria realidade. A partir do momento em que convivem com velhos que não apresentam os cabelhos brancos como indicativo de sua velhice, as crianças recorrem a outros sinais para reconhecer e justificar a atribuição de velhice a uma pessoa.

Bar - A minha vó tem cabelo branco e preto. (Menina, 6 anos)

Ent - Tem outra coisa na pessoa [além da cor dos cabelos mencionada anteriormente pela criança] que faz você pensar que ela é velha?

Afirma com a cabeça.

Ent - O quê?

Del-É porque um dia tinha uma mulher com cabelo tudo preto andando com uma bengala. Por isso que eu penso que ela é velha. (Menina, 9 anos)
As falas destacadas acima apontam que tanto a condição de avós quanto limitações e condições físicas são indicativas de velhice para as crianças. E, tendo em vista que a fala da maioria das crianças indica os avós e bisavós como referência de velhos, ganha destaque a categoria meu vô e minha vó.

Ent - É... como é que são as pessoas velhas?

Ant - O...a minha... a minha avó e o meu vô. (Menino, 6 anos)

A idéia de que os avós são velhos parece ser a primeira que ocorre às crianças quando questionadas sobre as pessoas velhas. No grupo de crianças maiores, quatro desenhos tinham como modelos os avós, enquanto no grupo de crianças menores, foram cinco os que continham avós e bisavós.

As pistas oferecidas nas falas das crianças indicam que elas estabelecem uma relação de sentido duplo, isto é, avós são velhos - como demonstrado na fala acima - e velhos são avós - quando dizem que para ficarem velhos, além de crescer, casar e ter filhos, terão netos. Os conceitos de velho e avós para essas crianças estão entrelaçados, sendo estes os velhos com os quais têm os primeiros e mais freqüentes contatos. Contudo, algumas exceções devem ser consideradas por revelarem que o papel exercido pelos avós influencia a relação entre esses conceitos. Duas crianças, do grupo de crianças maiores, vivem em lares em que os pais estão ausentes, sendo criados pelos avós. Ambas as crianças não consideram os pais-avós muito velhos.

Ent - Você acha que ela [a avó] é uma pessoa velha, ou não? And - Né muito não. (Menina, 9 anos)

Ent - Hum... e por que você acha que o seu avô e a sua avó que você desenhou aí são velhos?

Cri - Não é muito velho, né? Mas, eu... eu queria desenhar assim memo.

Ent - É... eles não são muito velhos não?

Cri - Não. A minha mãe é mais ou menos, o meu pai também². (Menino, 8 anos)

Ao contrário das crianças criadas pelos avós, tanto as crianças que vivem em lares multigeracionais, isto é composto por pais e avós, quanto as que vivem apenas com os pais e mantêm contatos periódicos com os avós, os reconhecem como velhos. Essa diferenciação indica que o ato de considerar os avós como velhos relaciona-se com o papel que estes desempenham frente às mesmas, não sendo os avós que atuam como pais considerados muito velhos, enquanto aqueles que atuam como avós o são.

A relação estabelecida entre velhos e avós pelas crianças, bem como a diferenciação citada indicam que estas ancoram a representação de velho ao modelo de avós definido por seu grupo social de pertença. Este modelo parece estar atrelado à demarcação apontada por Barros (1987), na qual amor, interesse e participação sem responsabilidade são atribuições dos avós, e educação, responsabilidade e criação fazem parte da função dos pais. Assim, conforme apontado por Lopes, Neri e Park (2005), há avós que são pais e avós que são avós. Para as crianças participantes desse estudo, estes são considerados velhos e aqueles não. Desse modo, percebe-se que a representação de velho dessas crianças se ancora à representação que têm de avós, 
a qual não se define baseada apenas na posição geracional, mas no significado social e simbólico que assume para o grupo.

A categoria adoecer e morrer surge a partir do momento em que doenças, limitações e dependências físicas foram conceitos utilizados pelas crianças para ancorar sua representação de velhos. Além disso, objetos de apoio tais como bengalas, muletas, cadeiras de rodas e óculos serviram para objetivar o conceito de velhos.

Ent - Como é que são as pessoas velhas?

Ali - Fica doente... (Menino, 6 anos)

Ent - O que elas têm? Como é que elas são, que fazem elas serem velhas?

Jac - Doença. (Menino, 9 anos)

As conversas com o grupo de crianças maiores revelam a existência de uma representação social do velho relacionada a doenças, limitações, fragilidade e morte. No que se refere a seus desenhos, dos setes analisados, dois continham bengalas, um apresentava bengala e cadeira de rodas, e outro, muletas. As crianças justificaram a presença desses objetos em seus desenhos de dois modos: afirmando que tais objetos estão relacionados aos velhos e relatando experiências pessoais em que os viram utilizando bengalas. Durante a brincadeira, a simulação de velhos utilizando bengala ou com dificuldades para andar foi freqüente nesse grupo.

No grupo de crianças menores, os velhos também foram relacionados a doenças, porém a associação com limitações físicas aconteceu com menor freqüência. Dos vinte desenhos apresentados, sete continham bengala e nenhum outro trouxe indícios de limitações físicas ou necessidade de objetos de apoio. Durante as entrevistas, as justificativas para a presença da bengala foram a dificuldade de locomoção e a experiência de tê-los visto com bengalas. Durante a brincadeira nesse grupo, esse tipo de caracterização deu-se apenas em dois momentos breves, não se estendendo durante a brincadeira e não sendo priorizado como forma de caracterizar os velhos como o foi no grupo de crianças maiores, indicando que a idéia de limitação física se faz presente de maneira menos marcante que para o outro grupo.

No que se refere à relação entre velhos e morte, esta foi ressaltada com maior freqüência pelas crianças maiores, as quais afirmaram que doenças e proximidade da morte fazem com que ser velho seja desagradável e indesejado. No grupo de crianças menores, apenas duas crianças estabeleceram uma relação direta entre velhice e morte, enquanto outras crianças relatavam a morte de avós ou bisavós.

A associação da velhice com doença, morte, perdas e limitações é feita desde que a vida foi periodizada sob influência de um modelo baseado em premissas biológicas, o que estigmatizou a velhice como um período de decadência e perdas. A veiculação das conclusões de certas pesquisas (Garrido \& Menezes, 2002; Lima-Costa, Barreto, \& Giatti, 2003; Ramos, Rosa, Oliveira, Medina, \& Santos, 1993), as quais indicam que os velhos apresentam mais problemas de saúde que a população geral, não se restringe aos meios científicos, alcançando a população pelos diversos canais de difusão de informações advindas do universo reificado. Assim, a idéia de que o velho é mais doente que indivíduos de outros grupos etários disseminase e, elaborada pelos grupos sociais, agrega-se às outras que participarão da representação social do velho e da velhice.

Alguns estudos (Araújo \& Carvalho, 2004; Santos, 2002; Veloz et al., 1999) indicam que em diversos grupos sociais a representação social sobre o velho, a velhice e o envelhecimento ancora-se no conceito de limitações físicas e principalmente doença, assim como se deu no grupo de crianças participantes deste estudo. Desse modo, há indícios de que as mesmas têm construído sua representação social acerca do velho com base em informações que já circulam na sociedade em que estão inseridas, acabando por perpetuar a idéia de que ser velho é sinônimo de estar doente e próximo à morte.

Ao contrário do que se poderia inferir a partir da relação estabelecida entre velho e morte, doenças e limitações físicas, para as crianças os velhos não estão segregados. Segundo elas, o velho circula pela cidade, sendo encontrado em suas casas e pelas ruas em atividades diversas. A partir das afirmações das crianças a esse respeito, surge a categoria temática num monte de lugar.

Ana - Porque a gente, quando a gente anda na rua, a gente vê pessoa velha. (Menina, 6 anos)

And - Outro dia eu fui na praça, né, num show. Daí tinha um mo... um velho que tava passando em frente, sabe, no show que tinha lá em Jarinu esse dia? (Menina, 10 anos)

Na representação dessas crianças, os velhos circulam pela cidade, nas praças, nas ruas, nas festas públicas, bem como nas casas de amigos e familiares, não estando circunscritos a um espaço exclusivo e/ou excludente. $\mathrm{O}$ fato de viverem em uma cidade pequena, cujos habitantes distribuem-se por bairros com características rurais, pode servir como elemento facilitador para a circulação e a integração dos velhos à comunidade.

No que se refere à moradia, os velhos residem em suas próprias casas, sozinhos, com cônjuge ou com os filhos, sendo que o asilo como opção de moradia foi apontado por duas crianças do grupo de crianças maiores em seus desenhos e durante a entrevista. Os demais desenhos dessas crianças continham as casas dos velhos desenhadas. No grupo de crianças menores, 12 desenhos continham as casas dos velhos. Vale ressaltar que três crianças mencionaram a possibilidade dos velhos morarem nas ruas. Durante as entrevistas, verificou-se que a menção a essa possibilidade se relacionava às experiências vivenciadas ao visitar cidades maiores, onde é mais comum a presença de mendigos nas ruas. Relacionava-se ainda às referências que fizeram aos velhos como pobres ou mendigos, sem dinheiro, nem comida, conforme haviam tido contato por meio de programas televisivos ou experiências pessoais.

Outro ponto a ser destacado no discurso das crianças diz respeito às indicações de que os velhos são ativos, podem trabalhar e realizar atividades variadas, laborais ou não, delimitando a categoria fazem um monte de coisa.

\footnotetext{
Ent - O que eles fazem? O que as pessoas velhas fazem?

Jam - Um monte de coisa. Trabalha...

Ent - Eles trabalham de que?

Jam - Tem alguns que trabalha na roça. (Menino, 6 anos)
} 
Ent - E o que ele tá fazendo?

Jac - Assistindo televisão.

Ent - É... ele costuma assistir à TV?

Jac - Humhum (confirmando).

Ent - O que você acha que uma pessoa velha, é... que ela costuma fazer assim no dia dela? Depois que ela acorda, o que ela costuma fazer o dia inteiro?

Jac - Fica fazendo tricô. (Menino, 9 anos)

Para a maioria das crianças, especialmente as menores, o trabalho é uma atividade do velho. Nos poucos casos em que mencionaram que os velhos não trabalhavam, referiam-se principalmente às mulheres, posto que as atividades domésticas não eram consideradas trabalho. Entretanto, mesmo quando não eram considerados trabalhadores, os velhos não foram classificados como inativos ou ociosos, sempre lhes sendo conferida alguma atividade.

As atividades mencionadas relacionaram-se à realidade vivenciada pelas crianças, girando os exemplos em torno de tarefas domésticas para as mulheres e de atividades rurais para os homens. Tal fato associa-se à realidade rural, o contexto social em que vivem, no qual o desligamento do trabalho devido à idade, ou mesmo devido à aposentadoria não é uma regra, conforme indicam Albuquerque, Lôbo e Raimundo (1999). Usualmente, os velhos continuam a trabalhar em suas pequenas propriedades ou mesmo como empregados, na medida em que se sentem aptos para tal. As mulheres também não se desvinculam das atividades domésticas, as quais são significadas como um dever feminino independente da idade. Assim, a realidade vivenciada por essas crianças, pertencentes a um grupo social de menor poder aquisitivo e vinculado às atividades rurais, mostra-lhes que os velhos são ativos, contrariando o estigma de inativos que, conforme ressaltado por Pacheco (2005), costuma circular pela sociedade.

Na representação dessas crianças sobre o velho, os indícios da heterogeneidade estão presentes. Os velhos não são iguais e, a partir dessa informação se erigiu a categoria tudo é diferente. Assim, mesmo havendo conformidade acerca de determinadas idéias, as crianças em entrelinhas ou mesmo de maneira explícita, indicam que sabem da existência de outras possibilidades. O momento da brincadeira junto às crianças maiores mostrouse revelador dos indícios dessa variedade de idéias acerca dos velhos. Num primeiro momento, eles são representados como debilitados, com limitações para se locomover. Depois, trabalham, dirigem, circulam pela cidade, viajam.

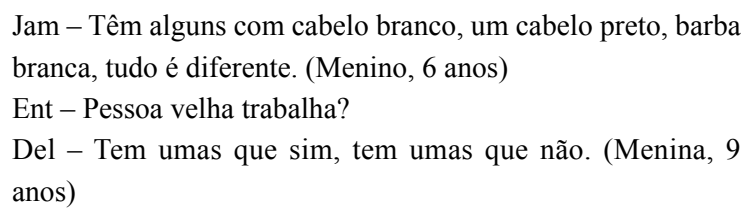

As falas das crianças, permeadas por diferentes informações, podem inicialmente parecer contraditórias. Todavia, as informações oferecidas por elas indicam que apreendem, elaboram e incorporam à sua representação acerca dos velhos, as diferentes imagens que a sociedade tem apresentado. Essas crianças representam os velhos como ativos, que ainda trabalham, não têm cabelos brancos, moram em suas próprias casas, podem viajar, estudar, ir ao cinema e namorar. Tais atributos podem ser encontrados na imagem de velhice bem-sucedida ou terceira idade ativa propagada pela mídia com o objetivo de criar um novo mercado consumidor. Por outro lado, representam os velhos como pobres, doentes, acamados, enrugados e com cabelos brancos. Estas características fazem-se presente em outra imagem propagada, relacionada à dependência, perdas $\mathrm{e}$ improdutividade.

As representações sociais são construídas pelos sujeitos a partir de informações que circulam na sociedade e que lhe causam certa estranheza, numa tentativa de incorporar o conflitante e torná-lo familiar (Moscovici, 2005). As crianças, membros de um grupo de atores sociais, participam também do processo de construção e reconstrução da representação social acerca do velho, na sociedade contemporânea, resultado da coexistência de imagens que parecem conflitantes acerca desse objeto social.

\section{O envelhecer: porque uma pessoa é velha}

Segundo as crianças, o envelhecimento é um processo relacionado à passagem do tempo, a um ciclo natural ao qual todos estão sujeitos.

Num momento de diálogo com o grupo de crianças maiores durante a brincadeira tematizada, estas afirmaram que demorará para que fiquem velhos e que para tal é preciso crescer, estudar, casar, ter filhos e netos. Algumas crianças ressaltam que ficarão grandes e depois velhos.

Isa - Porque ela fez bastante... é... aniver...aniversário. (Menina, 6 anos)

Ana - Porque, é... porque, quando a gente é nova a gente também fica velha. (Menina, 6 anos)

A passagem do tempo indica o envelhecimento para as crianças. Elas sabem que com o passar do tempo, as pessoas envelhecem, inclusive elas mesmas. É preciso crescer, cumprir os deveres sociais (estudar, trabalhar, casar), procriar e ver os filhos crescerem, então a velhice terá chegado.

Almeida e Cunha (2003), em seu estudo acerca da representação social do desenvolvimento humano, encontraram evidências de que o conhecimento social sobre o tema está calcado em bases científicas, havendo uma seqüência de fases de caráter universal e irreversível que seguem um processo evolutivo, conforme as propagadas pela Psicologia do Desenvolvimento. O conhecimento sobre o ciclo da vida definido como uma sucessão de etapas a serem cumpridas, circula então, pela sociedade, baseado na experiência do viver cotidiano e na elaboração de teorias científicas acerca do desenvolvimento humano, as quais se incorporam nas representações sociais a respeito do tema.

\section{Considerações finais}

Encontrou-se, junto aos grupos de crianças que participaram desse estudo, a convivência de diferentes conceitos em suas representações sociais sobre os velhos. As aparentes contradições encontradas no discurso das crianças poderiam levar a pensar 
na existência de incoerências. Todavia, relacionando o conteúdo da representação das crianças com as fontes de informações de que dispõem e o contexto social em que vivem, percebe-se que a representação é coerente com sua realidade. As representações sociais são construídas com base nas informações que circulam pela sociedade, nas relações sociais e no movimento do grupo no qual nascem, transformam-se e podem se extinguir, sendo importante conhecer o contexto em que são produzidas para que sejam compreendidas (Jodelet, 2005). Considerando-se então, a diversidade de informações sobre os velhos que circulam pela sociedade em que esses pequenos atores sociais estão inseridos, torna-se fácil compreender as diferenças que convivem em sua representação social sobre os mesmos.

A convivência de tantas informações sobre o velho e o envelhecimento pode indicar um momento de transição, do qual sobressairá apenas uma das tantas imagens propagadas ou mesmo uma miscelânea destas. Esse momento pode ser visto como uma oportunidade para que seja reforçada a heterogeneidade que circunda esses objetos sociais, contribuindo assim, para que esse aspecto passe a configurar como um dos elementos de suas representações sociais. Poder-se-ia minimizar, assim, preconceitos e estereótipos negativos usualmente relacionados ao velho e ao envelhecimento. Vale ressaltar, a necessidade de haver cautela, para que nesse processo não se incorra no erro de "glamourizar" a velhice. Faz-se necessário promover uma idéia polissêmica da velhice, isto é, uma idéia que congregue a heterogeneidade que lhe é própria e não seja distorcida por estereótipos e preconceitos, positivos ou negativos.

$\mathrm{O}$ presente estudo possui limitações no que se refere à desigualdade de participantes entre os grupos pesquisados, resultado do critério utilizado para a seleção dos mesmos, isto é, haver participado de encontros com velhos no contexto escolar. Vale ressaltar ainda, em relação a esse aspecto, o fato de que não houve intenção de comparar as representações sociais dos grupos e sim descrevê-las.

Estudos que busquem conhecer a representação social acerca do velho em grupos de crianças e de outras faixas etárias são pertinentes, tendo em vista que as novas imagens e informações sobre a velhice, os velhos e o envelhecimento que têm circulado pela sociedade, bem como, as alterações na configuração etária da população, contribuem para a (re)construção das representações sociais. Conhecer tais representações permite obter pistas sobre o modo como os indivíduos atuam e se relacionam com os velhos e com sua própria velhice.

\section{Referências}

Albuquerque, F. J., Lôbo, A. L., \& Raymundo, J. S. (1999). Análise das repercussões psicossociais decorrentes da concessão de benefícios rurais. Psicologia Reflexão e Crítica, 12(2), 503-519.

Almeida, A. M. O., \& Cunha, G. G. (2003). Representações sociais do desenvolvimento humano. Psicologia Reflexão e Crítica, 16(1), 147-155.

Araújo, L. F., \& Carvalho, V. A. M. L. (2004). Velhices: estudo comparativo das representações sociais entre velhos de grupos de convivência. Textos sobre Envelhecimento, 7(1). Disponível em $<$ www.unati.uerj.br>; acessado em 03/junho/2005.

Ariés, P. (1986). História social da criança e da família ( $2^{\mathrm{a}}$ ed.). Rio de Janeiro:
Guanabara.

Arruda, A. (2002). Teorias das representações sociais e teorias de gênero. Cadernos de pesquisa, (117), 127-147. Disponível em <www.scielo.br>; acessado em 13/fevereiro/2005.

Barreto, M. L. (1992). Admirável mundo velho: velhice, fantasia e realidade social. São Paulo: Ática.

Barros, M. L. (1987). Autoridade e afeto: avós, filhos e netos na família brasileira. Rio de Janeiro: Jorge Zahar.

Beauvoir, S. (1990). A velhice (5ª ed.). Rio de Janeiro: Nova Fronteira.

Debert, G. G. (1999). A reinvenção da velhice: socialização e processos de reprivatização do envelhecimento. São Paulo: Edusp, Fapesp.

Duveen, G. (2005). Introdução: o poder das idéias. In S. Moscovici (Org.), Representações sociais: investigações em Psicologia social (pp. 7-28). Petrópolis: Vozes.

Duveen, G., \& Lloyd, B. (2005). Introduction. In G. Duveen, \& B. Lloyd. (Orgs.), Social representations and the development of knowledge (pp. 1-10). Nova York: Cambridge University Press.

Featherstone, M. (1998). O curso de vida: corpo, cultura e imagens do processo de envelhecimento. In G. G. Debert (Org.), Antropologia e velhice. Textos didáticos (2 ${ }^{\underline{a}}$ ed.; pp. 45-64). Campinas: IFCH/ UNICAMP.

Garrido, R., \& Menezes, P. R. (2002). O Brasil está envelhecendo: boas e más notícias por uma perspectiva epidemiológica. Revista Brasileira de Psiquiatria, 24(supl. I), 3-6.

Jodelet, D. (2005). Loucuras e representações sociais. Petrópolis: Vozes.

Lichtenstein M. J., Pruski L. A., Marshall C. E., Blalock C. L., Lee S., \& Plaetke R. (2003). Sentence completion to assess children's views about aging. The Gerontologist, 43(6), 839-848.

Lima-Costa, M. F., Barreto, S. M., \& Giatti, L. (2003). Condições de saúde, capacidade funcional, uso de serviços de saúde e gastos com medicamentos da população idosa brasileira: um estudo descritivo baseado na Pesquisa Nacional por Amostra de Domicílios. Cadernos de Saúde Pública, 19(3), 735-743.

Lopes, E. S L. (2006). Crianças e velhos no projeto Jarinu tem memória: representações sociais e significados. Dissertação de Mestrado não-publicada, Universidade Estadual de Campinas.

Lopes, E. S. L., Neri, A. L., \& Park, M. B. (2005). Ser avós ou ser pais: os papéis dos avós na sociedade contemporânea. Textos sobre Envelhecimento, 8(2), 239-253.

Magro, V. M. M. (2003). Espelho em negativo: a idade do outro e a identidade etária. In N. M. M. Gusmão (Org.), Infância e velhice: pesquisa de idéias (pp. 33-46). Campinas: Átomo e Alínea.

Moscovici, S. (1978). A representação social da Psicanálise. Rio de Janeiro: Zahar.

Moscovici, S. (2005). Representações sociais: investigações em psicologia social. Petrópolis: Vozes.

Newman, S., Faux, R., \& Larimer, B. (1997). Children's views on aging: their attitudes and values. The Gerontologist, 37(3), 412-417.

Novaes, M. R. V., \& Derntl, A. M. (2002). As imagens da velhice: o discurso do sujeito coletivo (DSC) como método de investigaçäo. Mundo Saúde, 26(4), 503-508.

Pacheco, J. L. (2005). Sobre aposentadoria e envelhecimento. In J. L. Pacheco, L. Py, \& J. L. Sá (Orgs.), Tempo: rio que arrebata (pp. 59-73). Holambra: Setembro.

Park, M. B. (2000). Comunidade, memória e formação de professores. In Memória em movimento na formação de professores: prosas e histórias (pp. 17-38). Campinas: Mercado de Letras.

Park, M. B. (2004). Prefácio. In L. Wild (Org.), Travessias: memórias do povoa mento de imigração de uma cidade paulista: Jarinu (pp. 9-19). Campinas: Mercado de Letras.

Pinquart, M., Wenzel, S., \& Sörensen, S. (2000). Changes in attitudes among 
children and elderly adults in intergenerational group work. Educational Gerontology, 26, 523-540.

Ramos, L. R., Rosa, T. E. C., Oliveira, Z. M., Medina, M. C. G., \& Santos, F. R. G. (1993). Perfil do idoso em área metropolitana na região sudeste do Brasil: resultados de inquérito familiar. Revista de Saúde Pública, 27(2), 87-94.

Sá, C. P. (1993). Representações sociais: o conceito e o estado atual da teoria. In M. J. Spink (Org.), O conhecimento no cotidiano: as representações sociais na perspectiva da psicologia social (pp. 19-45). São Paulo: Brasiliense.

Santos, G. A. (2002). Os conceitos de saúde e doença na representação social da velhice. Revista Virtual Textos e Contextos, 1. Disponível em < www.pucrs. br/textos>, acessado em 25/maio/2006.

Silveira, D. B. (2005). Falas e imagens: a escola de educação infantil na perspectiva das crianças. Tese de Doutorado não-publicada, Universidade Federal de São Carlos, São Carlos, SP.

Souza Filho, E. A. (1993). Análise de representações sociais. In M. J. Spink (Org.), O conhecimento no cotidiano: as representações sociais na perspectiva da psicologia social (pp. 109-145). São Paulo: Brasiliense.

Veloz, M. C. T., Nascimento-Schulze, C. M., \& Camargo, B. V. (1999). Representações sociais do envelhecimento. Psicologia: Reflexão e Crítica, $12(2), 479-501$

Notas

${ }^{1} \mathrm{O}$ presente artigo deriva de dissertação de mestrado defendida pela primeira autora, sob orientação da segunda. O trabalho foi apoiado pela Fundação de Assistência à Pesquisa do Estado de São Paulo - Fapesp.

${ }^{2}$ A criança referia-se aos avós usando os termos pai e mãe.

Ewellyne Suely de Lima Lopes é mestre em Gerontologia pela Universidade Estadual de Campinas. E-mail: ewllyne@yahoo.com.br

Margareth Brandini Park, doutora em Educação pela Universidade Estadual de Campinas, é pesquisadora no Centro de Memória da mesma instituição e professora no Programa de Pós-graduação em Gerontologia. Endereço para correspondência: Rua Laurindo Fonseca e Silva, 155, (Jardim Patrícia); Uberlândia, MG; CEP 38414-188. Tel.: (34) 3217-6905. E-mail: margareth.park@gmail.com 